Saudi Journal of Oral and Dental Research

Abbreviated Key Title: Saudi J Oral Dent Res

ISSN 2518-1300 (Print) |ISSN 2518-1297 (Online)

Scholars Middle East Publishers, Dubai, United Arab Emirates

Journal homepage: https://saudijournals.com/sjodr

\title{
Management of Class II Division I Malocclusion Compound with Orthopedic and Fixed Orthodontics Appliance - A Case Reputation
}

Dr. Mohammed Korayem ${ }^{1 *}$

${ }^{1}$ Assisstant Professor in Orthodontics, College of Dentistry Albaha University, Albaha, Saudi Arabia

DOI: $\underline{10.36348 / \text { sjodr.2020.v05i10.003 }}$

| Received: 26.09.2020 | Accepted: 09.10.2020 | Published: 16.10.2020

*Corresponding author: Dr. Mohammed Korayem

\section{Abstract}

Class II malocclusions are particular of utmost familiar complications in orthodontic management. Around is an assortment of effectual and effortless managements to accurate them, for instance fixed orthodontics appliances and headgear. These appliances are largely planned for management of class II deformities through lower arch defect. Accomplishment of management using a functional appliance depend on the patient's collaboration and favorable lower arch expansion. Subsequent period of management with full-fixed appliances frequently essential to accomplish accurate alignment and excellent interdigitating of the dentition. In the current case, a pre-pubertal 12 year female through a class II malocclusion and retrusive lower arch was cured first using a headgear aimed at 18 months. Headgear productively determined the predicament of retrusive lower arch with encouraging mandible development. It was subsequently nine months of fixed orthodontic management to conclude the occlusion restricted of extractions. Two stage treatment generated a gratifying shape as well as decent occlusion in particular patient.

Keywords: Fixed orthodontics appliances, class II malocclusion, headgear, functional appliances.

Copyright $(\mathbf{2 0 2 0}$ The Author(s): This is an open-access article distributed under the terms of the Creative Commons Attribution 4.0 International License (CC BY-NC 4.0) which permits unrestricted use, distribution, and reproduction in any medium for non-commercial use provided the original author and source are credited.

\section{INTRODUCTION}

Class II malocclusion defects are solitary of maximum mutual complications realized by an orthodontist. Popular developing patients, two-phase management of class II skeletal defects, that comprises growing moderation through functional usages examined by orthodontic management with fixed applications, has been fortified equally an applicable cure technique $[1,2]$. For instance through altogether orthodontic management methods, the most important aims of development.
Moderation is mutually in the direction of accurate the undernourished divergence to accomplish optimum superficial aesthetics. Numerous critical satisfaction has been accredited headed for the management of class II deformities next to a premature time: anticipation of pain just before upper incisors additional using enormous overjet, interference of emerging defective, emotional rewards intended for child through an imperative developmental phase of lifespan, and advanced diagnosis used for adolescent segment of management [3].
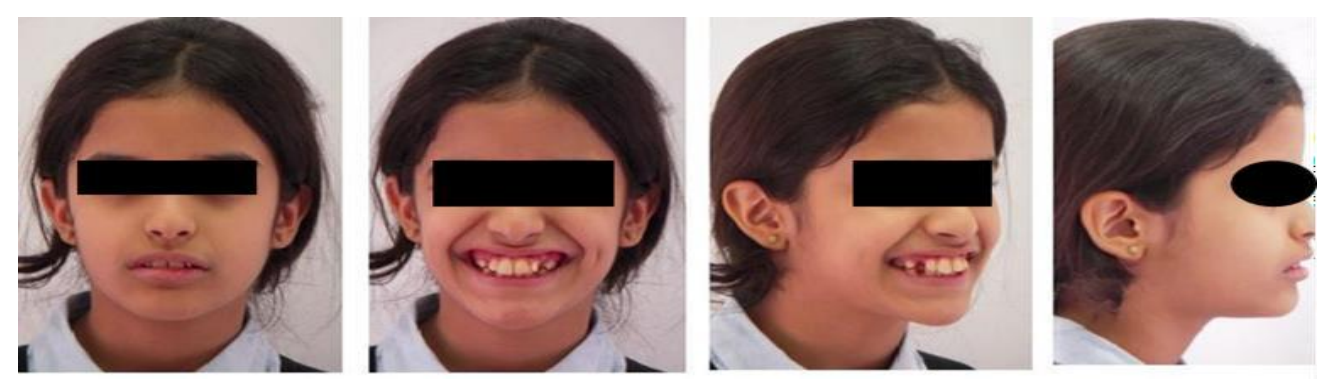

(a) 

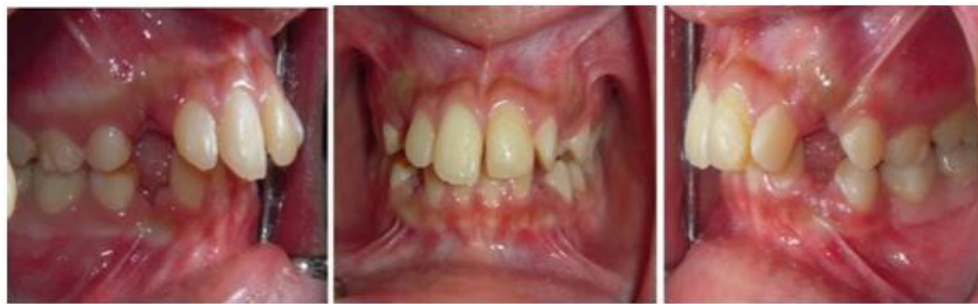

(b)
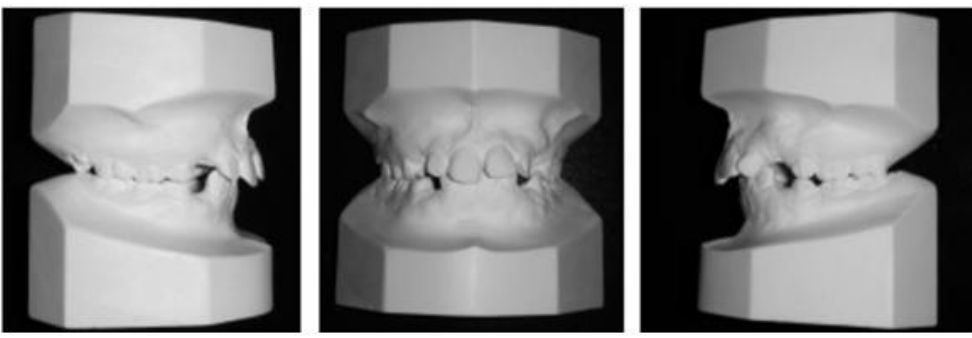

(c)

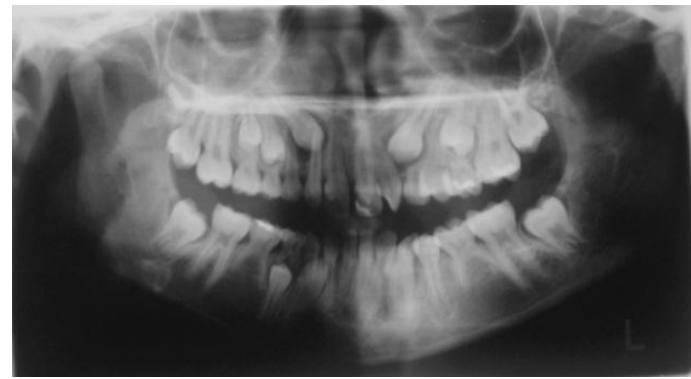

(e)

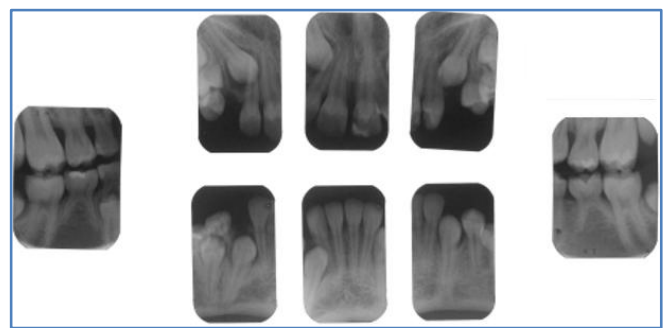

(d)

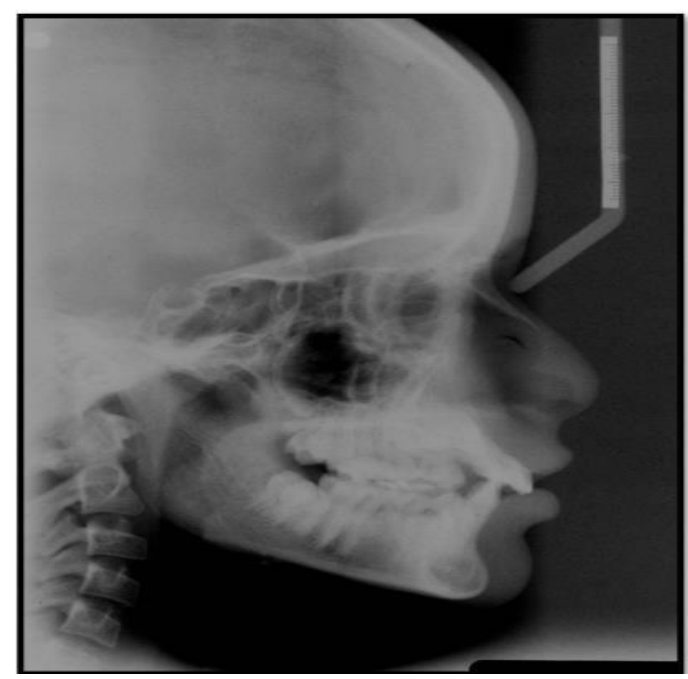

(f)

\section{BACKGROUND}
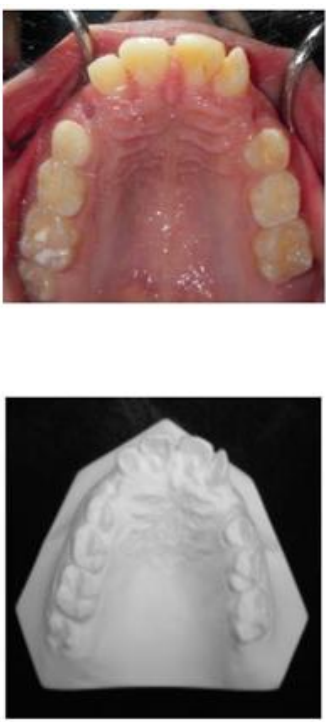

Fig-1: (a)-Pre-treatment extraoral photographs. (b) Pretreatment intraoral photographs. (c) Pre-treatment orthodontic study models. (d) Pre-treatment panoramic radiograph. (e) Pre-treatment intra oral periapical radiograph. (f) Pre-treatment cephalogram.

Table-1: Pre-treatment cephalometric examination

\begin{tabular}{|c|c|c|c|}
\hline Area of Study & Sagittal Relationship & & \\
\hline Maxillary Relation & SNA & $82^{\circ} \pm 2^{\circ}$ & $\underline{82^{\circ}}$ \\
\hline Mandibular Relation & SNB & $80^{\circ} \pm 2^{\circ}$ & $78^{\circ}$ \\
\hline Basal Arch Relation & ANB & $2^{\circ} \pm 2^{\circ}$ & $\underline{4}^{\circ}$ \\
\hline \multirow[t]{2}{*}{ Wits Appraisal } & Wits Appraisal & -1 to $0 \mathrm{~mm}$ & $+1 \mathrm{~mm}$ \\
\hline & SN-Pog & $80^{\circ} \pm 3^{\circ}$ & $79^{\circ}$ \\
\hline Angle of convexity & NA-A Pog & $0^{\circ} \pm 5.1^{\circ}$ & $\underline{6^{\circ}}$ \\
\hline \multirow[t]{2}{*}{ Cranial base Angel } & NSBa & $130^{\circ} \pm 6^{\circ}$ & $133^{\circ}$ \\
\hline & Vertical Relationship (Div) & & \\
\hline SN to Palatal Plane & SN to Palatal PI. & $8 \circ \pm 3 \circ$ & $10^{\circ}$ \\
\hline SN to Man Plane & SN to Mand. PI. & $32 \circ \pm 5.1$ & $\underline{27^{\circ}}$ \\
\hline Palatal Plane to Man & Palatal PI. to Mand. PI. & $25^{\circ} \pm 3^{\circ}$ & $\underline{22^{\circ}}$ \\
\hline Y-Axis & Y-Axis (N-S-Gn) & $59.4^{\circ} \pm 3.8^{\circ}$ & $60^{\circ}$ \\
\hline Jaw Angle & Me-tgo-Ar & $126 \pm \pm 10^{\circ}$ & $121^{\circ}$ \\
\hline \multirow[t]{2}{*}{ Face Height } & (ANS-Me/N-Me) & $55 \% \pm 3 \%$ & $54 \%$ \\
\hline & Dental Relationship & & \\
\hline Intericisal ANgle & U Inc. to L Inc. & $131^{\circ} \pm 5^{\circ}$ & 113 \\
\hline Max Incisor to SN & $\mathrm{U}$ Inc. to $\mathrm{SN}$ & $104^{\circ} \pm 2^{\circ}$ & 115 \\
\hline Max Incisor to PP & U Inc. to Palatal PI. & $110^{\circ} \pm 6^{\circ}$ & 122 \\
\hline Max Incisor to NA & U Inc. to NA & $22 \circ \pm 5 \circ(4 m m \pm 3)$ & $31 / 9 \mathrm{~mm}$ \\
\hline Man Incisor to NB & L Inc. to NB & $25^{\circ} \pm 6 ॰(4 \mathrm{~mm} \pm 2)$ & $\underline{31 / 4 \mathrm{~mm}}$ \\
\hline Man Incisor to APog & L Inc. to A Pog & $1 \mathrm{~mm} \pm 2 \mathrm{~mm}$ & $2 \mathrm{~mm}$ \\
\hline \multirow[t]{2}{*}{ lower inc to Man P. } & L Inc. to Mand. PI. & $93^{\circ} \pm 6^{\circ}$ & $\underline{96}$ \\
\hline & Soft Tissue Relationship & & \\
\hline Upper Lip to E/SNV-line & UL to EL & $-4 \mathrm{~mm} \pm 2 \mathrm{~mm}$ & $-2 / 2 \mathrm{~mm}$ \\
\hline Lower Lip to E/SNV-line & LL to EL & $-2 m m \pm 2 m m$ & $0 / 0 \mathrm{~mm}$ \\
\hline Naso-labial Angle & NLA & $90 \circ-110^{\circ}$ & 95 \\
\hline
\end{tabular}

Consistent with McNamara the furthermost recurrent skeletal delinquent now class II deformities happening pre adolescents is lower arch retrognathia. Therefore, several appliances that establish capability to encourage notable mandible development would be a substantial improvement in the direction of an orthodontist accumulation. Innate hypothesis has substantiated that uses which location the mandibular anteriorly can encourage noteworthy mandible 
development, predominantly through heightened remodelling reaction by condylar section $[5,6]$.

Persistence of practical treatment is towards modification the efficient situation of dentition near encouraging customary purpose [7]. Furthermost of efficient appliances are premeditated near augment the onward progression of lower arch by reassuring a practical dislocation of mandible condyles descending and onward in glenoid fossa. It is collected through an ascending and retrograde attraction in the strengths ancillary the lower arch.

Modifying restoration may proceed on equally articular faces of Tempro mandibular joint to increase the location of the lower arch relation to upper arch $[6$, 7]. Two of the utmost commonly recycled efficient applications for orthopedics modification of class II skeletal deformities castoff useful purposes are the headgear with anterior bite plane [8].

Headgear and the aforementioned beneficiaries deliver a superior connection extent through upper arch teeth and lingual mucosa besides consequently is supplementary operative in motivating the patient to situation the mandibular onward relentlessly.

Along with alteration of jaw development, the special properties of a headgear furthermore comprise proclamations of mandibular incisors and retroclination of maxillary incisors subsequent now a reduction in overjet. Headgear heaps the lingual planes of mandibular incisors that can procline the progressively due to one-sided intermaxillary adhesion whereas patient obstructs keen on the manufacture bite.

Orthodontics association can be familiar our improvement in management if mandibular incisors have made retroclined teeth and proclined maxillary incisors because of lip habits frequently perceived in those through an improved overjet. Regardless of the situation modest scheme, a headgear can be familiar alteration orthodontics connection in altogether three level surface of gap using appropriate correction $[1,5]$. An additional current efficient application is anterior bite plane.

As a result of the situation modest policy and simplicity of practical, it is conceivable worn out $24^{\text {th }}$ hour a day and proceeds complete benefit of entirely practical services practical to orthodontics, comprising the particular muscles of mastication. Additional improvement of anterior bite plane is that it could be practiced along with fixed appliances $[7,8]$.

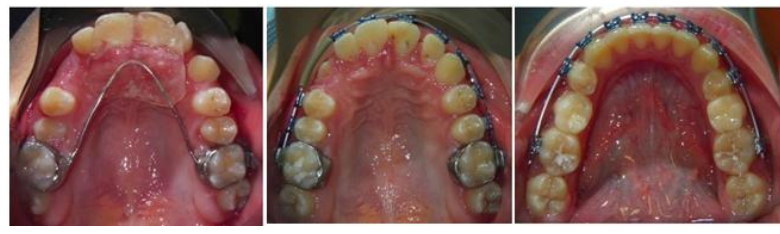

(a)

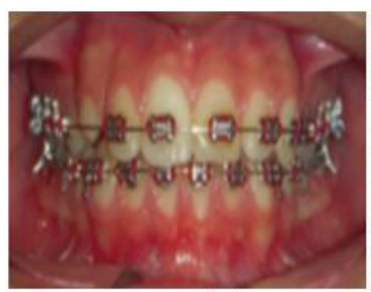

(b)

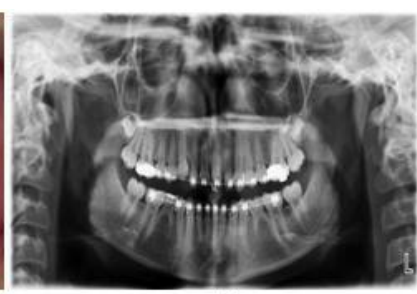

(c)
Fig-2: (a, b) during treatment intraoral photographs. (c) During treatment panoramic radiograph.

\section{Analytic findings, examination and history}

Twelve year female patient obtainable to Orthodontics department, by primary complaint of proclined maxillary central incisors. Analysis of case was supported on view subsequent a consistent procedure monitored by orthodontist and shortened in this:

\section{Extra oral examination}

- Anterior view

- Facial asymmetry: Outwardly asymmetrical

- Incisor contact: $4 \mathrm{~mm}$ active

- Facial thirds: Interactive

\section{Shape Assessment}

- Facial outline: U-shaped

- Lip protuberance: Projected with lower lip

- deception

- Chin: Declining

\section{Radioactive results}

- Bony sagittal class II with regular deviating jaw centers with forward placed maxillary and mandibular central incisors.

- $\quad$ MP3 (development status): F stage

Visual treatment objective (VTO) Progressive

\section{Symptoms}

Angle's class II division 1 malocclusion on a bony class II regular deviating jaw centers through occurrence of modest tongue thrust and maxillary lip sucking pattern.

\section{Management design}

In view of bony and dental divergence two management methods were assumed applicable: 


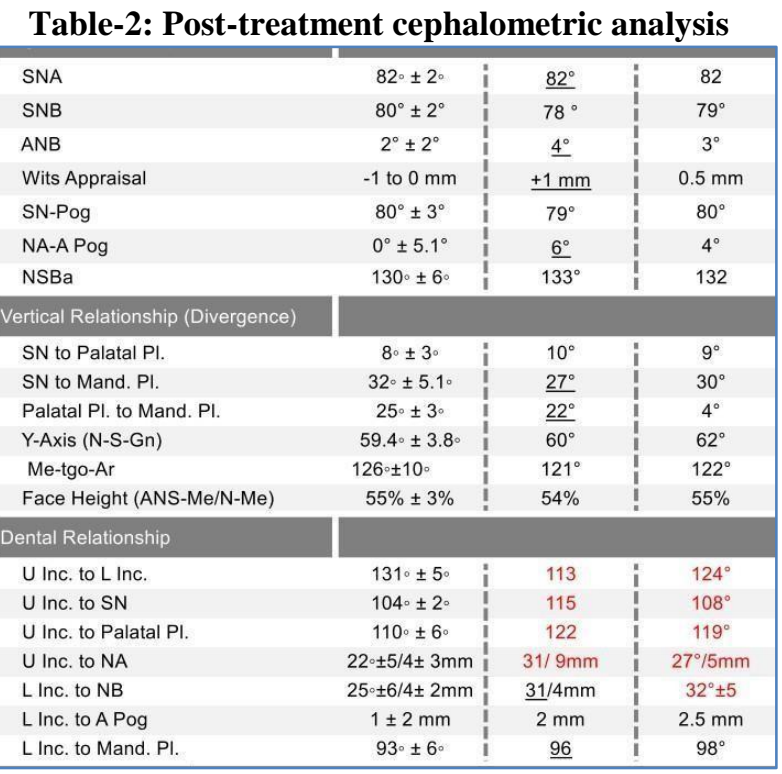

- Efficient application to accurate fundamental bony inconsistency surveyed through fixed mechano therapy intended designed for concluding specifying.

- Two stage management design was considered additional suitable used for this example and the patient's parent acquiesced aimed at this strategy concerned the price benefit proportion existence, leeway of space of bony inconsistency and option to extravagance through without extraction. Nevertheless, by an improved management effectiveness and additional charge elaborate. Encouraging VTO was greatest incentive for the blood relation to select aimed at this approach.

\section{Stage I management: efficient appliance analysis}

\section{Appliance assortment}

Anterior bite plane using headgear or anterior bite plane unaccompanied compared to headgear. An anterior bite plane using headgear was primary select by means of it delivered security of purpose, development of lower arch, constraint of upper arch development. Conversely, was not utilized unpaid to numerous apprehensions of the close relative being:

- Patient was a hosteled consequently would not be underneath their administration aimed at suitable headgear procedure.

- Teenagers might clown her, oppose throughout production that could reason her damage.

- They will not be instantaneously accessible to appear to her in occurrence of any unexpected trendy and instructors next to department might be minute assistance in treatment similar consequence.

- Selection development was to remain retained to negligible such as blood relation departed to appreciate child impartial ended the visit and department was distant so thoroughly located schedules would necessitate lost the institute habitually.

- Allowing for a fore revealed apprehension an application was required that was informal to procedure, substantial sufficient not to interruption effortlessly or mislead through a moment of uneven management, essential insignificant preparation. A headgear was zero e-das application of excellent aimed at this circumstance for the reason that:

- Precise accessible

- Durable

- Engagements spaced separately

- Might effortlessly be unconcerned throughout performance otherwise in the course of course limiting hazard of damage or else distress through communication. Alongside, different anterior bite plane that has a maxillary and mandibular block, headgear is an only section application that supplementary lessens accidental of longsuffering misplacing single associate and overcoming the persistence of management.

- Finally, sound paraphernalia of twin block and activator management has been accepted to remain parallel [6].

Perpendicular elevation of five millimeters in the bicuspid area with improvement of six millimeter was scheduled. Meanwhile, development of lower arch ensued in cross bite a development attach was integrated used for diagonal lower arch growth that was to remain stimulated each stay when the close relative departed to see the teenager. It had numerous benefits existence, firstly, attach was correctly stimulated equally engaged, close relative had fortuitous near perceive appliance frequently consequently slightly uncultured misrepresentations might be noticed and blood relation were unswervingly elaborate in their youngster's behavior and henceforth were interested in the direction of remain and reassure teenager to collaborate accordingly decreasing failure as of analysis. The labial bow was divided to consent designed for arch addition in the direction of occur.

\section{Purpose and selection planning}

Intricate presentation maintenance teaching was enlightened to patient. She was examined to practice the application subsequently meal about eight past morning to seven at morning and afterwards impending as of courses till accepted aimed at performance in late afternoon that unevenly additional extra three hour, an increasing to nearby $14^{\text {th }}$ a day and slightly further period once she was permitted.

Earlier two schedules were spread out on a week intermission towards evaluate security and acquiescence of patient. The enduring was 
tremendously supportive by application practice. Subsequently, recollection was programmed by sixty days separately aimed at slightly modifications required and discriminating crushing of points to convey the eruption of dentition.

\section{Find out about}

Discriminatory crushing of resinoid outline was accomplished in the direction of permit adult teeth outbreak through level I management. Patient had respectable acquiescence and conserved moral sounded hygiene. Maxillary occlusion was delayed to accurate buccal cross bite with gap achieved in anterior section was on the way to be cast-off getting on throughout secure mechano-therapy aimed at interference and withdrawal that might be compulsory. Subsequently 17 months of stage I management, patient displayed an upgraded countenance outline and consensual excellent Class I molar and cuspid attachment. Extreme curve of spee of maxillary arch was furthermore pointed next to discerning crushing near reassure mandibular posterior teeth eruption. In the meantime, patient similarly achieved her menarche near the conclusion of efficient period.

\section{Stage II management: fixed mechanotherapy}

Management purpose indulgent primary stage management was to analyst overjet with accurate class II molar relationship, though purpose of stage II management was on the way to complete respectable inter digitation deprived of extractions.

Circumstance was impecunious active after first molar into first molar expending 0.022inch period; metallic braces; retuned Edgewise Application a classification of 0.014 inch, 0.018 inch and Unitek Nitinol Temperature-Stimulated wires were recycled aimed at make parallel monitored through 0.018inch untainted stainless steel. Disrobing of mandibular anterior to increase around $3.5 \mathrm{~mm}$ gap was approved available and gap was conducive meant for up-rooting as well as interrupting the mandibular anterior.

Concluding accomplish was completed through 0.014inch spotless Stainless steel wire using small class II gum band. The secure application segment procured ten months near accomplishment.

\section{Preservation}

Covering about appliance through anterior bite plane were assumed intended for all time practice for one year and subsequently midnight adoption for six month life.

\section{Precarious assessment of behavior outcome}

Abundant studies have displayed that catalyst control the dent alveolar section primarily [1-10]. Nevertheless, here are approximately influences completed orthopedics paraphernalia of instrument. Despite the fact selected writer's entitlement that bony

outcome of headgear analysis is accredited to obstructive of lower arch growth, remains influence outlook that headgear encourages condylar as well as consequently lower arch grow[10,1]. An importance taking place glenoid fossa remodeling has been recounted through various employees $[1,3]$.

In this scenerio nonetheless, when management fluctuations were associated through pretreatment, care efficient and post usage super obligations a numerousness of dent alveolar variations concluded bony.

Well-designed period of analysis appropriated 18 months that was extended than normal. Suggestion overdue was in the direction of consent satisfactory period for cartilage upgrade to follow, further permitting phase for adult teeth to develop. Overall period of management was 28 months that might have been compact near around 17 months had merely secure mechano therapy been implemented through maxillary bicuspid extraction. Nevertheless, causing damage to misplacing double in good shape teeth; short of advantage of rectification of fundamental bony inconsistency in addition to the pattern, that, if persevered might have far along led to space primary next to extraction position. Patient with her caretaker were fascinated through treatment outcome.
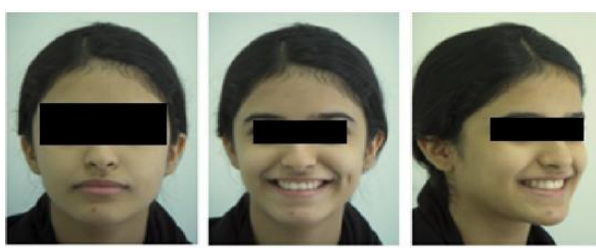

(a)
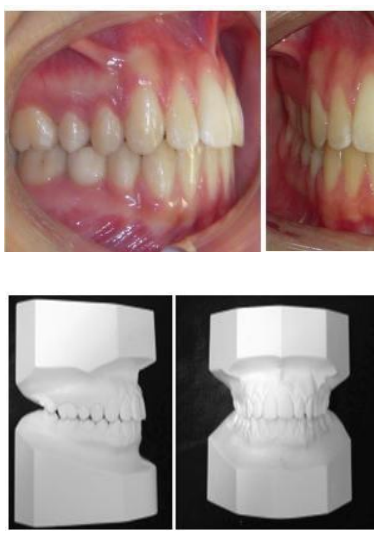

(b)

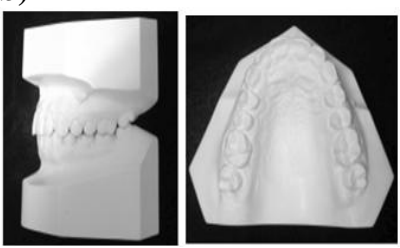

(c)

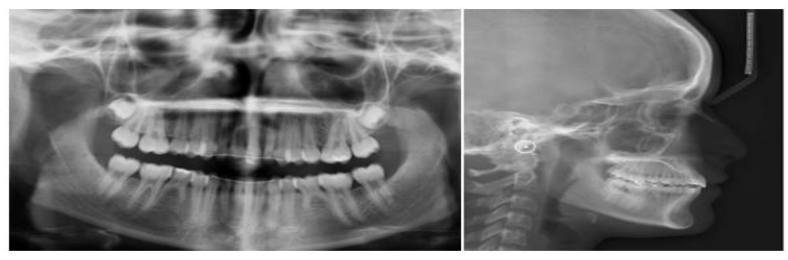

(d) 


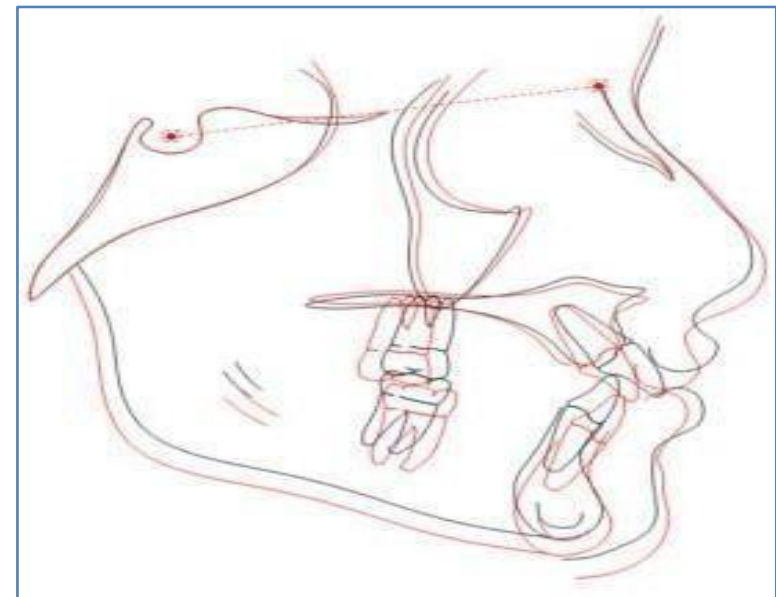

(f)

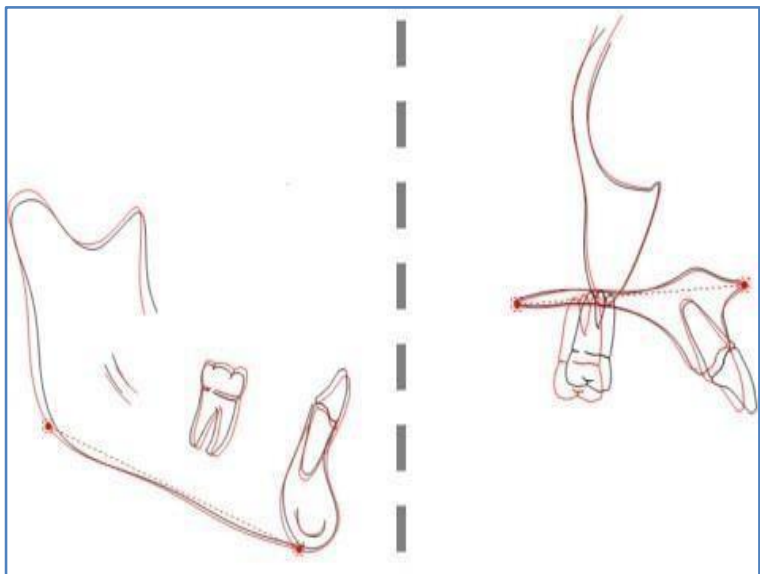

(g) Fig-3: (a)- Post-management extra oral photographs. (b) Post-management intra oral photographs. (c) Posttreatment orthodontic study models. (d) Post-treatment panoramic radiograph. (e) Post-treatment cephalogram. (f) Pre and post treatment Superimposition Structural Method. (g) Pre and post-treatment superimposition structural method

\section{CONCLUSION}

This situation description grants an effective management of a class II division 1 deformity by two phase analysis accurately retaining triumvirate of three equally in efficient appliance analysis: right attitude, right age with right appliance. An agreeable orthodontic facial profile was accomplished using removal of lower lip deception through rectification of tongue thrust habit and lip sucking pattern. Bicuspid and molar relationship was consensually class I through midplanes identical and overjet of $3 \mathrm{~mm}$ and overbite of $2.8 \mathrm{~mm}$. At hand was a slender thickness popular the smile, that was visually satisfactory allowing for that long-suffering may perhaps have approximately remaining elastics tissue development enduring that will recover it concluded period.

\section{REFERENCES}

1. Pachori, Y, Navlani, M, Gaur, T., \& Bhatnagar, S. (2012). Treatment of skeletal class II division 1 malocclusion with mandibular deficiency using myofunctional appliances in growing individuals. Journal of Indian Society of Pedodontics and Preventive Dentistry, 30(1), 56.

2. Clark, W. (2010). Design and management of Twin Blocks: reflections after 30 years of clinical use. Journal of orthodontics, 37(3), 209-216.

3. Perinetti, G., \& Contardo, L. (2017). Reliability of growth indicators and efficiency of functional treatment for skeletal Class II malocclusion: current evidence and controversies. BioMed research international, 2017.

4. Clark, W. (2010). Design and management of Twin Blocks: reflections after 30 years of clinical use. Journal of orthodontics, 37(3), 209-216.

5. Bishara, S. E., \& Ziaja, R. R. (1989). Functional appliances: a review. American Journal of Orthodontics and Dentofacial Orthopedics, 95(3), 250-258.

6. Wahl, N. (2006). Orthodontics in 3 millennia. Chapter 9: functional appliances to midcentury. American journal of orthodontics and dentofacial orthopedics, 129(6), 829-833.

7. Julyan, J. C., \& Coetsee, M. (2018). Class II Division 1 treatment using a two-phase approach-a case report. Cell, 74(136), 3505.

8. DiBiase, A. T, Cobourne, M. T., \& Lee, R. T. (2015). The use of functional appliances in contemporary orthodontic practice. British Dental Journal, 218(3), 123-128.

9. Johnston, L. E. (1996). Functional appliances: a mortgage on mandibular position. Australian orthodontic journal, 14(3), 154.

10. Toth, L. R., \& McNamara Jr, J. A. (1999). Treatment effects produced by the Twin-block appliance and the FR-2 appliance of Fränkel compared with an untreated Class II sample. American Journal of Orthodontics and Dentofacial Orthopedics, 116(6), 597-609. 